\title{
Triaxial tests and DEM simulation on artificial bonded granular materials
}

\author{
Honglin Lin $^{\text {i) }}$ and Jianhong Zhang ${ }^{\text {ii) }}$
}

i) Ph.D Student, Department of Hydraulic Engineering, Tsinghua University, Beijing, 100084 China. ii) Professor, Department of Hydraulic Engineering, Tsinghua University, Beijing, 100084 China.

\begin{abstract}
This paper presents a study on a bonded granular material based on consolidated drained triaxial tests and Distinct Element Method (DEM) analysis. Steel balls of $5 \mathrm{~mm}$ in diameter and a metal bonding, i.e. Scotch-weld MC 100, were used to simulate granular material and the bonding between particles. Triaxial consolidation drained tests were conducted on the artificial bonded granular material. The effect of bonding on the mechanical properties is analyzed. The triaxial tests were reproduced with Particle Flow Code (PFC). Comparison of the experimental and numerical results was made. It is indicated that the intergranular cementation has a significant effect on the mechanical properties such as strength, deformation. The bonded granular material exhibits strain softening behavior.
\end{abstract}

Keywords: discrete element method, bonded granular, triaxial test

\section{INTRODUCTION}

Interparticle bonding can significantly influence the structure and stress-strain relationship of granular materials (Leroueil et al., 1990). Macroscopic mechanical properties of granular mixtures greatly depend on its mesoscopic characteristics (Jiang et al., 2006; Jung et al., 2011). However, it may be difficult to determine the micro parameters associated with interparticle bonding as it is unevenly distributed. Laboratory tests, such as triaxial test, are often used to identify key features of the interparticle bonding and its effect on the mechanical properties (Yun et al., 2007; Wang \& Leung., 2008). Numerical method also plays an important role in simulation of the behaviour of the bonded granular material (Brugada et al., 2010; Jung et al. 2012).

This paper suggests a simple method to prepare an artificial bonded granular material. Triaxial consolidation drained tests were conducted on the artificial bonded granular material and reproduced with $\mathrm{PFC}^{3 \mathrm{D}}$. Comparison of the test and numerical results was made. The effect of microscopic bonding on the macro mechanical properties is discussed.

\section{SPECIMEN PREPARATION}

For the experimental study, the purpose is to find a material with properties analogue to sand but more easily to create bonding between particles. Nevertheless, stable bonding and adequate curing time between particles is crucial to avoiding discrete micro parameters. In this study, commercially available stainless steel balls were used to prepare specimens for triaxial tests. The diameter of the steel ball is $5 \mathrm{~mm}$. The density of the steel is $4.93 \times 10^{3} \mathrm{~kg} / \mathrm{m}^{3}$. The Elastic modulus is 193 GPa. The Poisson's ratio is 0.27 . With the steel balls, it was easy to make a specimen with simple mesoscopic fabric that can be well reproduced in numerical simulation. Specimens of unbonded steel balls were made with procedures identical to sand specimen preparation.

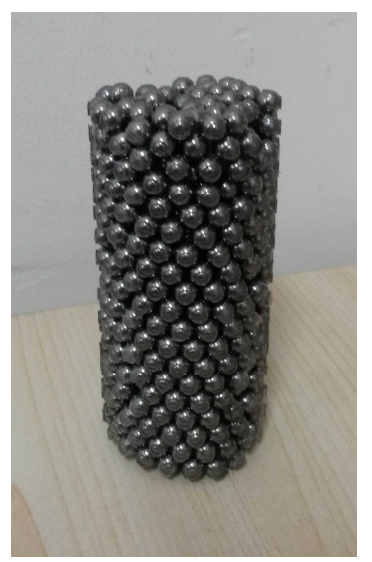

Fig. 1. Specimen of artificially bonded steel balls

Procedures for preparing a specimen of bonded steel balls were as follows: 1) The steel balls were placed in the plexiglass mold of $39 \mathrm{~mm}$ in diameter and $800 \mathrm{~mm}$ in height to form a uniform specimen. 2) A liquid metal bonding, i.e. Scotch-weld MC 100, was slowly dripped into the mold to fill the pore space. It had strong bonding strength and formed cementation contact between balls in a few minutes. 3) The specimen was cured at indoor condition for $24 \mathrm{~h}$ before testing. 


\section{EXPERIMENTAL STUDY}

\subsection{Test procedure}

The consolidated drained triaxial tests (ASTM 7181) were conducted on unbonded and bonded specimens under confining pressures of $\sigma_{3}=100,300$ and $500 \mathrm{kPa}$ respectively. The rate for shearing is 0.30 $\mathrm{mm} / \mathrm{min}$. The test will at an end when the axial strain reached $15 \%$. Dimensions of the unbonded and bonded specimens were measured (Table 1). The slight difference was owing to the preparation method and presence of the bonding. The number of balls in each specimen was also counted.

Table 1. Parameters of unbonded and bonded specimens

\begin{tabular}{lll}
\hline Parameter & $\begin{array}{l}\text { Unbonded } \\
\text { specimens }\end{array}$ & $\begin{array}{l}\text { Bonded } \\
\text { specimens }\end{array}$ \\
\hline Diameter $(\mathrm{mm})$ & 38.6 & 39.3 \\
\hline Height $(\mathrm{mm})$ & 83.0 & 84.0 \\
\hline Number of balls & 1100 & 1150 \\
\hline Porosity & 0.35 & 0.35 \\
\hline
\end{tabular}

\subsection{Experimental results}

Fig. 2 shows the stress-strain relationship of unbonded balls under confining pressures of 100,300 and $500 \mathrm{kPa}$. It is similar to the behavior of dense sand. Fig. 3 gives the Mohr-Coulomb envelope based on the triaxial tests. The effective cohesion is $8 \mathrm{kPa}$, approaching to zero. The effective friction angle of is $24^{\circ}$, slightly greater than that of stainless steel, i.e. $17-22^{\circ}$. It indicates that relative sliding between balls is the main mechanism in shearing.

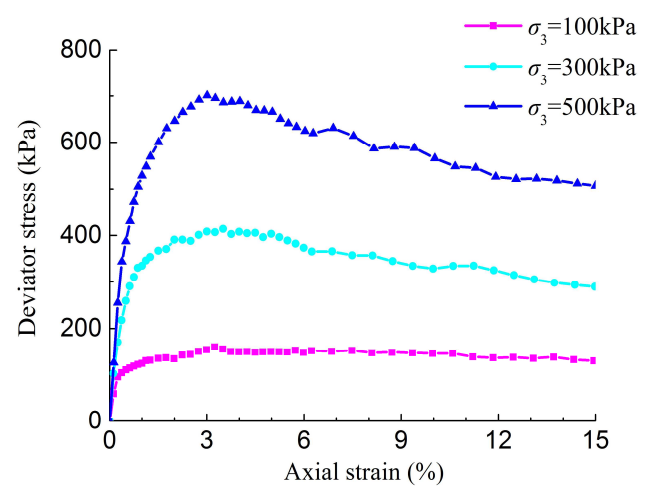

Fig. 2. Stress-strain relationship of unbonded balls

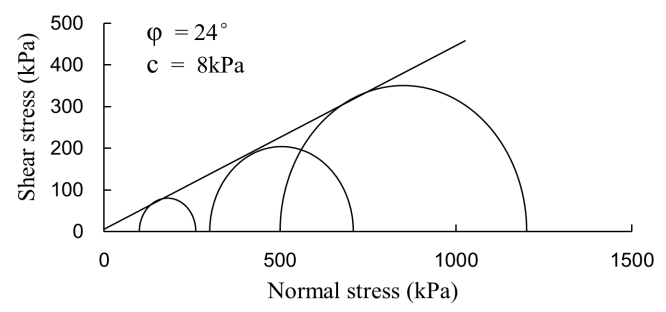

Fig. 3. Mohr-Coulomb envelope of unbonded balls

Fig. 4 shows the stress-strain relationship of bonded balls under confining pressures of $\sigma_{3}=100,300$ and $500 \mathrm{kPa}$. Fig. 5 gives the Mohr-Coulomb envelope of the bonded material in terms of the triaxial tests. The effective cohesion of bonded balls is $315 \mathrm{kPa}$. The effective friction angle is $43^{\circ}$. Fig. 6 compares the stress-strain behavior of unbonded and bonded specimens under a confining pressure of $300 \mathrm{kPa}$.

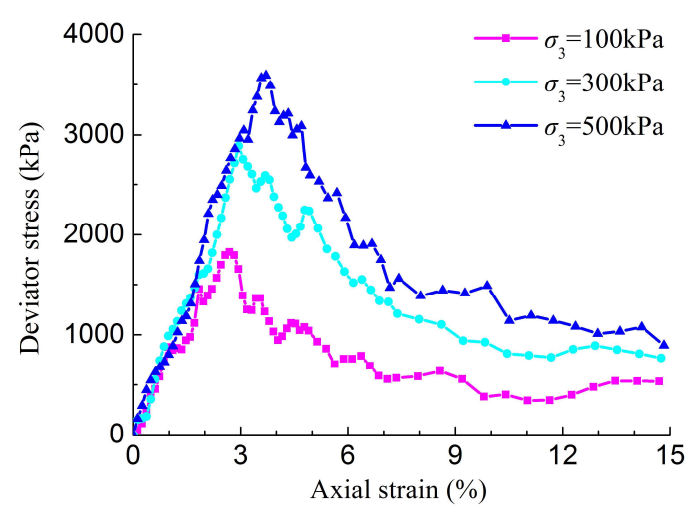

Fig. 4. Stress-strain relationship of bonded balls

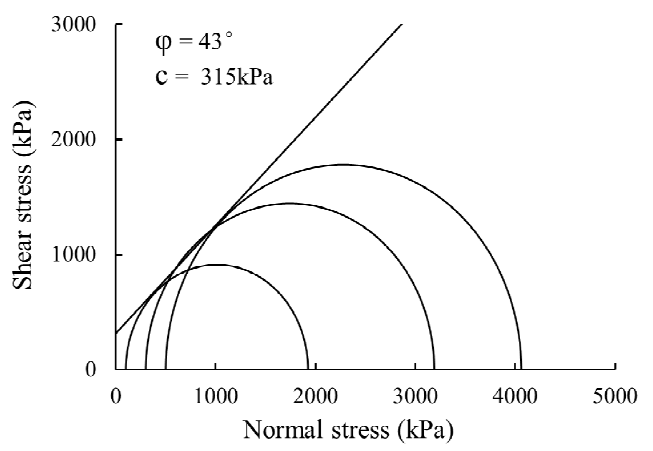

Fig. 5. Mohr-Coulomb envelope of bonded balls

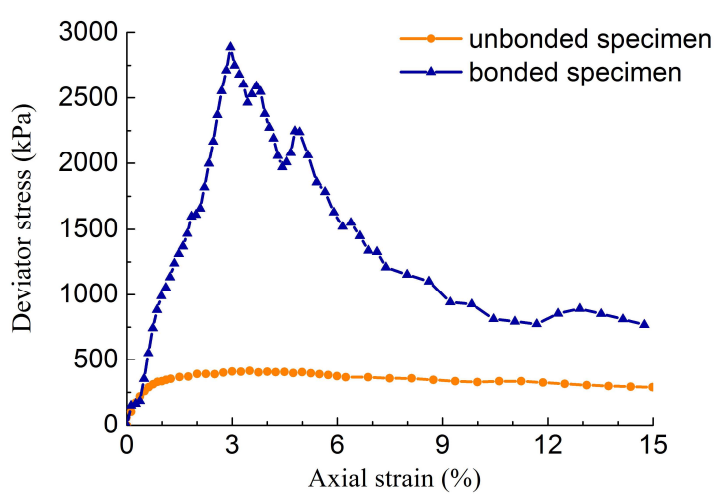

Fig. 6. Stress-strain relationships of unbonded granular materials and bonded granular materials in $300 \mathrm{kPa}$

Comparing test results of the unbonded and bonded materials, it indicates that: 1) The bonds between balls greatly increase the strength of the specimen. Both cohesion and internal friction angle of bonded balls are much greater than that of unbonded balls. 2) The mechanisms of bonded balls in shearing include bond breaking and relative sliding between balls. The stress-strain curve for bonded balls is unsmooth owing to the involvement of bond breaking. 3) Before reaching the peak strength, the bonds constrain the sliding of 
the steel balls and thus increase the strength and modulus. 4) After reaching the peak strength, extensive bond breaking allows balls sliding and leads to strength dropping, as shown in Fig. 4. 5) Strength softening is more significant for bonded balls in shearing. The residual strength is also higher than unbonded balls.

\section{NUMERICAL SIMULATION}

\subsection{Simulation method}

The experimental tests were reproduced using commercially available discrete element code Particle Flow Code in Three Dimensions v3.10 ( $\left.\mathrm{PFC}^{3 \mathrm{D}}\right)$. In terms of $\mathrm{PFC}^{3 \mathrm{D}}$, a contact between particles is simulated by a contact-stiffness model, a slip model and a bonding model (Itasca, 2003). The contact-stiffness model can be a linear model or nonlinear model. This paper only presents the numerical results with the nonlinear model. The nonlinear contact-stiffness model is defined by a shear modulus and a Poisson's ratio.

\subsection{Parameters used in numerical simulation}

It is assumed that the steel balls uniformly distributed in the specimen, and the geometric parameters of the particles and the specimens are identical to that in the triaxial tests (Table 1). The density of steel balls and the interparticle friction coefficient of unbonded granular specimens were determined in terms of the parameters of stainless steel. The interparticle friction coefficient of bonded balls was estimated through the numerical simulation. The nonlinear contact-stiffness model is used to simulate particle contact, the two parameters, i.e. shear modulus of $77.0 \mathrm{GPa}$ and the Poisson's ratio of 0.27 are assumed to be the parameters of the stainless steel. Model parameters are summarized in Table 2.

The membrane and permeable stones are modeled as a lateral wall and loading wall contact defined in $\mathrm{PFC}^{\mathrm{BD}}$ by the linear contact-stiffness model. The parameters of the wall contact are listed in Table 3. The cementation between balls was simulated by the parallel-bond model, of which the parameters are estimated through numerical simulation (Table 4).

Table 2. Parameters used in DEM simulation

\begin{tabular}{lll}
\hline Parameter & $\begin{array}{l}\text { Unbonded } \\
\text { specimens }\end{array}$ & $\begin{array}{l}\text { Bonded } \\
\text { specimens }\end{array}$ \\
\hline Shear rate $(\mathrm{mm})$ & 0.3 & 0.3 \\
\hline Diameter $(\mathrm{mm})$ & 38.6 & 39.3 \\
\hline Height $(\mathrm{mm})$ & 83.0 & 84.0 \\
\hline Number of balls & 1100 & 1150 \\
\hline Porosity & 0.35 & 0.35 \\
\hline Inter-particle friction & 0.30 & 0.70 \\
\hline Shear modulus $(\mathrm{GPa})$ & 77.0 & 77.0 \\
\hline Poisson's ratio & 0.27 & 0.27 \\
\hline
\end{tabular}

Table 3. Parameters of wall contact.

\begin{tabular}{lcc}
\hline & Normal stiffness $(\mathrm{N} / \mathrm{m})$ & Shear stiffness $(\mathrm{N} / \mathrm{m})$ \\
\hline Lateral wall & $7.8 \times 10^{4}$ & $7.8 \times 10^{4}$ \\
\hline Loading wall & $5.0 \times 10^{8}$ & $5.0 \times 10^{8}$ \\
\hline
\end{tabular}

Table 4. Parameters for parallel-bond model.

\begin{tabular}{ll}
\hline Parameters & Values \\
\hline Normal bonding stiffness $(\mathrm{N} / \mathrm{m})$ & $4.0 \times 10^{15}$ \\
\hline Shear bonding stiffness $(\mathrm{N} / \mathrm{m})$ & $4.0 \times 10^{15}$ \\
\hline Normal bonding strength $(\mathrm{Pa})$ & $2.0 \times 10^{12}$ \\
\hline Shear bonding strength $(\mathrm{Pa})$ & $2.0 \times 10^{12}$ \\
\hline Bond disk radius $(\mathrm{mm})$ & 1 \\
\hline
\end{tabular}

\subsection{Numerical results}

Figs. 7 and 8 compare the experimental and numerical results of unbonded and bonded specimens. With the model parameters described above, the calculated stress-strain response is primarily identical to the triaxial test. More conspicuous deference appears under a confining pressure of $\sigma_{3}=100 \mathrm{kPa}$, as indicated in Figs. 7 and 8. When the confining pressure increases, the calculated stress-strain tends to be more close to the experimental results.

In addition, the simulations of the triaxial tests carried out using linear contact model have the similar results.

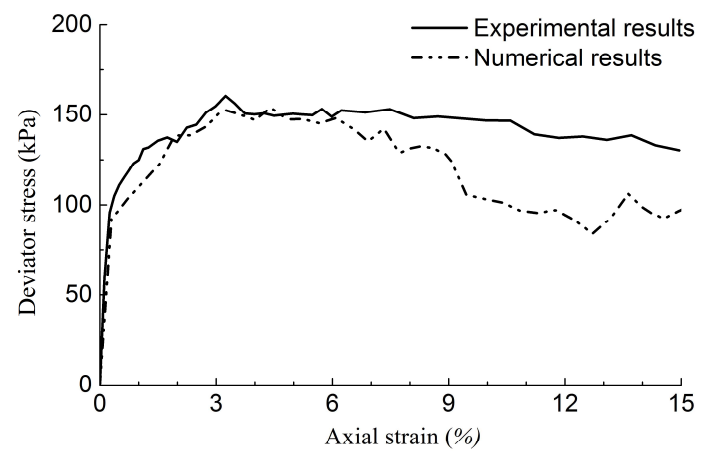

(a) $\sigma_{3}=100 \mathrm{kPa}$

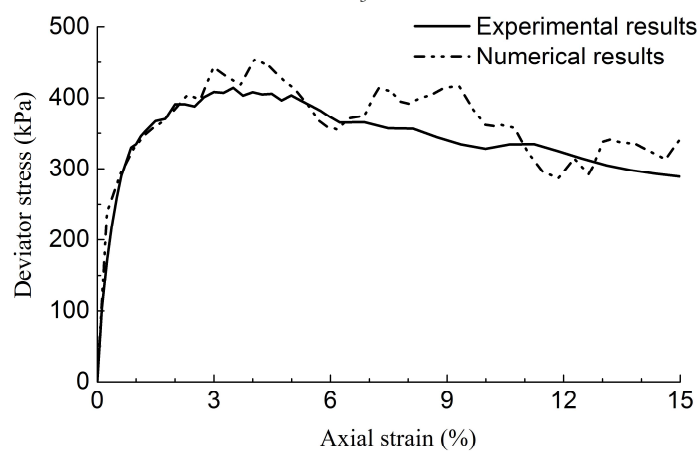

(b) $\sigma_{3}=300 \mathrm{kPa}$

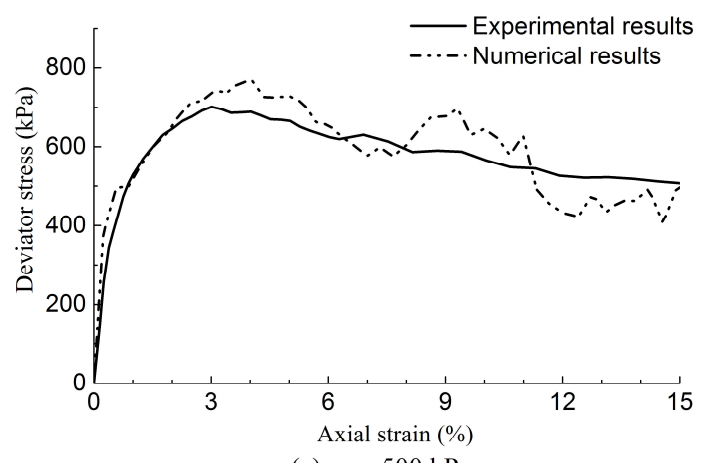

(c) $\sigma_{3}=500 \mathrm{kPa}$

Fig. 7. Comparisons between experimental and numerical results of unbonded specimens. 


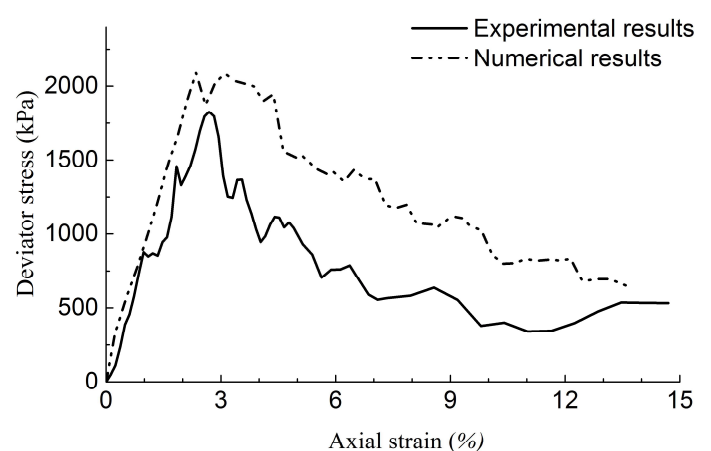

(a) $\sigma_{3}=100 \mathrm{kPa}$

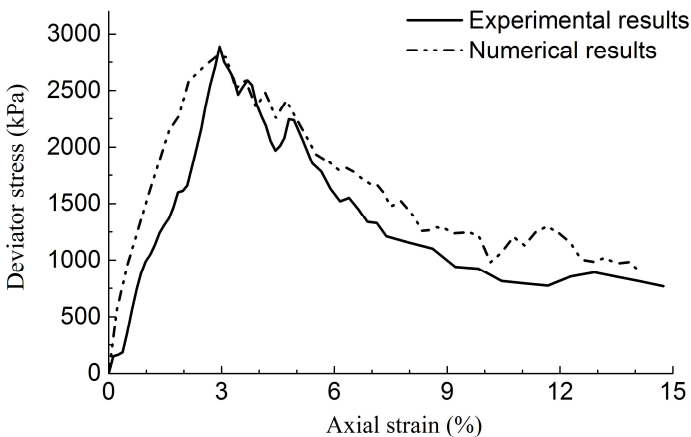

(b) $\sigma_{3}=300 \mathrm{kPa}$

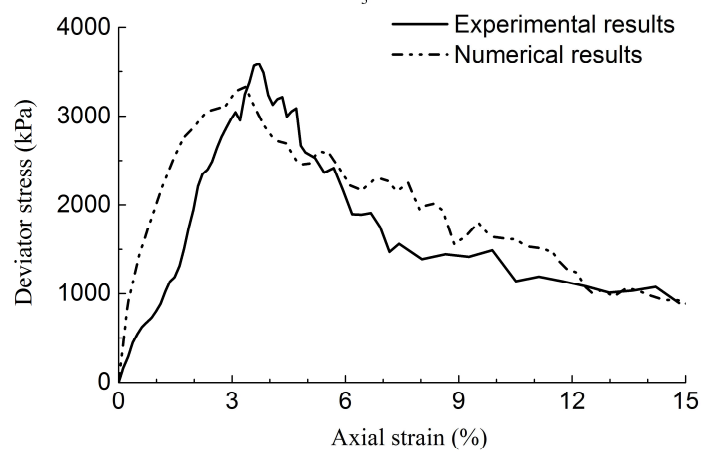

(c) $\sigma_{3}=500 \mathrm{kPa}$

Fig. 8. Comparisons between experimental and numerical results of bonded specimens

Moreover, with the parallel-bonded model, the numerical simulation reproduces some important characters of the bonded material: 1) The stress fluctuation or dropdown due to bond breaking in shear can be well simulated. 2) The strain softening behavior of the bonded specimen can be well described. 3) The peak strength of the material can be reproduced under different confining pressure.

The numerical results also indicate that: 1) Both the contact-stiffness model and the bonding model can reasonably describe the behavior of the particle contact. Detailed investigation on the contact behavior and its effect may be needed. 2) The numerical method is able to capture the main features of the unbonded and bonded material. The micro parameters for bonding and particles are reasonable. The discrete element method is thus verified and can be used to simulate the behavior of the bonded granular material.

\section{CONCLUSIONS}

This paper suggests a simple method to prepare an artificial bonded granular material. Based on triaxial consolidation drained tests and distinct element analysis, the effect of microscopic bonding on the macro mechanical properties of bonded granular material is discussed.

1) The specimen composed of steel balls and metal bonding has simple fabric that can be well reproduced in numerical model.

2) Bonds between particles greatly increase the strength of the material. The mechanisms of bonded material in shearing include bond breaking and particle sliding.

3) The numerical method is able to capture the main features of the unbonded and bonded material with the micro parameters of bonding and particles.

\section{ACKNOWLEDGEMENTS}

The research program was funded by the National Basic Research Program of China (2013CB035902) and the State Key Laboratory of Hydroscience and Engineering Project (2013-KY-04, 2014-KY-03).

\section{REFERENCES}

1) Brugada, J., Cheng, Y. P., Soga, K. and Santamarina, J. C. (2010). Discrete element modelling of geomechanical behaviour of methane hydrate soils with pore-filling hydrate distribution. Granular Matter, 12(5), 517-525.

2) Itasca. (2003). "PFC3D: Particle flow code. User' s guide" version 3.0. Minneapolis, USA.

3) Jiang, M. J., Yun, H. S. and Harris, D. (2006). Bond rolling resistance and its effect on yielding of bonded granulates by DEM analyses. International Journal for Numerical and Analytical Methods in Geomechanics, 30(8), 723-761.

4) Jung, J. W., and Santamarina, J. C. (2011). Hydrate adhesive and tensile strengths. Geochemistry, Geophysics, Geosystems, 12(8).

5) Jung, J. W., Santamarina, J. C., \& Soga, K. (2012). Stress strain response of hydrate - bearing sands: Numerical study using discrete element method simulations. Journal of Geophysical Research: Solid Earth (1978-2012), 117(B4).

6) Leroueil, S. and Vaughan, P. R. (1990). The general and congruent effects of structure in natural soils and weak rocks. Geotechnique, 40(3), 467-488.

7) Standardization Administration of the P.R.C. and General Administration of Quality Supervision, Inspection and Quarantine of P.R.C. (2007). Stainless steel and heat resisting steel grades and chemical composition. Beijing: China Standards Press.

8) Wang, Y. H. and Leung, S. C. (2008). A particulate-scale investigation of cemented sand behavior. Canadian Geotechnical Journal, 45(1), 29-44.

9) Yun, T. S., Santamarina, J. C. and Ruppel, C. (2007). Mechanical properties of sand, silt, and clay containing tetrahydrofuran hydrate. Journal of Geophysical Research: Solid Earth (1978-2012), 112(B4). 